\title{
Dietary behaviors related to cancer prevention among pre-adolescents and adolescents: the gap between recommendations and reality
}

\author{
Dawn M Holman ${ }^{*}$ and Mary C White
}

\begin{abstract}
Background: Diet is thought to play an important role in cancer risk. This paper summarizes dietary recommendations for cancer prevention and compares these recommendations to the dietary behaviors of U.S. youth ages 8-18.

Methods: We identified cancer prevention-related dietary recommendations from key health organizations and assessed dietary consumption patterns among youth using published statistics from the National Health and Nutrition Examination Survey, the national Youth Risk Behavior Survey, and other supplemental sources.

Results: Cancer prevention guidelines recommend a diet rich in fruits, vegetables, and whole grains, recommend limiting sugary foods and beverages, red and processed meats, sodium, and alcohol, and recommend avoiding foods contaminated with carcinogens. However, youth typically do not meet the daily recommendations for fruit, vegetable, or whole grain consumption and are over-consuming energy-dense, sugary and salty foods.

Conclusions: A large discrepancy exists between expert recommendations about diet and cancer and actual dietary practices among young people and points to the need for more research to better promote the translation of science into practice. Future research should focus on developing and evaluating policies and interventions at the community, state and national levels for aligning the diets of youth with the evolving scientific evidence regarding cancer prevention.
\end{abstract}

\section{Introduction}

The consensus among scientists in the field of cancer control is that diet plays an important but not fully understood role in modifying cancer risk and that certain changes in the American diet could have a beneficial impact on cancer occurrence [1-6]. However, diets are complex, and different components in the diet have been hypothesized to operate through different mechanisms throughout the process of cancer development. Accurately measuring dietary intake also poses many methodological challenges [7]. As a result, the contribution of diet to cancer risk is difficult to estimate with any degree of scientific certainty [8-10]. Although the benefits may be difficult to quantify, it has been proposed that efforts to align dietary consumption patterns

\footnotetext{
* Correspondence: isc6@cdc.gov

Epidemiology and Applied Research Branch, Division of Cancer Prevention and Control, Centers for Disease Control and Prevention, 4770 Buford Highway NE, Mailstop K-55, Atlanta, GA 30341, USA
}

among American youth with cancer prevention recommendations could reduce lifetime cancer risk as well as improve overall health $[4,11]$. This paper summarizes current dietary recommendations for cancer prevention and compares these recommendations to the dietary behaviors of pre-adolescents and adolescents in the United States (U.S.). Identifying gaps between dietary recommendations and the diets of youth will help to inform and direct future research and intervention efforts.

\section{Methods}

\section{Data sources and study selection}

We used a targeted approach to identify the most recent cancer prevention-related dietary recommendations of key organizations, including the American Academy of Pediatrics (AAP), American Cancer Society (ACS), American Heart Association (AHA), American Institute for Cancer Research (AICR), International Agency for

\section{Ciomed Central}


Research on Cancer (IARC), U.S. Department of Health and Human Services (HHS), U.S. Department of Agriculture (USDA), World Cancer Research Fund International (WCRF), and World Health Organization (WHO). We used National Institutes of Health (NIH) PubMed and the National Guideline Clearinghouse to search for additional information on dietary recommendations published from 2000 to present.

To assess dietary patterns among youth in the U.S., we used published statistics based on data from the National Health and Nutrition Examination Survey (NHANES) [12] and the national Youth Risk Behavior Survey (YRBS) [13], as well as supplementary information available on the USDA website [14]. NHANES is a continuous, nationally representative, cross-sectional survey. A dietary interview component of NHANES is conducted as a partnership between USDA and HHS [15]. Two in-person, 24-hour food recall interviews are conducted with each individual [15]. Additional information on the dietary collection methods is available elsewhere $[12,15]$. NHANES body mass index (BMI) data comes from height and weight measurements taken during data collection [15]. The sample sizes for the various NHANES statistics cited in this paper ranged from 1667 to 6087 youth within the age range of 12-19 years [16-23]. The national YRBS is a school-based survey that has been conducted since 1990 and uses a three-stage cluster sample design to produce a nationally representative sample of students in grades 9-12 [13]. Students complete the self-administered questionnaire in school during one class period. The national YRBS includes questions about fruit, vegetable, and soda consumption in the past seven days, lifetime alcohol use, alcohol use in the past thirty days, height, weight, and self-described weight status, in addition to questions about other health-risk behaviors [13]. The statistics cited in this paper from the 2009 national YRBS included 16,410 students from 158 schools [13]. Published results include current prevalence rates of health-risk behaviors and information on changes over time for each variable based on logistic regression analyses that controlled for sex, grade, and race/ethnicity and that simultaneously assessed linear and quadratic time effects [13]. We obtained information regarding youth exposure to carcinogenic food contaminants from the Fourth National Report on Human Exposure to Environmental Chemicals, a CDC publication which uses blood and urine samples collected as part of NHANES to assess exposure of the U.S. population to chemicals in the environment [24].

\section{Data extraction}

We grouped dietary recommendations for cancer prevention by dietary factors. For example, we grouped all recommendations regarding fruit consumption together and all recommendations regarding consumption of red and processed meat together. We further organized recommendations by association with a decreased cancer risk and association with an increased cancer risk. We extracted corresponding statistics on dietary behaviors of youth from the previously described sources.

\section{Results}

Current dietary guidelines and recommendations include recommendations that are thought to be relevant for reducing lifetime cancer risk. These guidelines and recommendations are based primarily on expert opinion, informed largely by observational epidemiologic studies that have linked dietary factors with either an increased or decreased risk in one or more cancers in adults. For cancer prevention, the focus has been on increasing the consumption of foods associated with a decreased cancer risk and limiting or avoiding foods associated with an increased cancer risk.

Foods thought to be associated with a decreased cancer risk include fruits, vegetables, and unprocessed, whole grains, and current recommendations for these foods are summarized in Table $1[1-3,25,26]$. In addition, guidelines to reduce the development of obesity in children are indirectly related to cancer prevention, because obesity has been associated with cancer occurrence at several sites among adults [1-3,27-29]. Dietary guidelines to prevent obesity emphasize a reduction in the consumption of foods with low nutritional value and high energy density, such as refined sugars and sugar-sweetened beverages $[25,26]$.

The consumption of some food items may increase the risk of cancer because of the presence of carcinogenic substances in these items, either naturally occurring or resulting from storage or preparation. Foods thought to be associated with an increased cancer risk include red and processed meats, salt, alcohol, foods contaminated with mycotoxins such as aflatoxin, and arsenic-contaminated water $[1-3,25,26]$. Current recommendations for food items associated with an increased cancer risk are summarized in Table 2.

\section{Fruits and vegetables}

Although current guidelines emphasize a diet rich in fruits and vegetables $[1-3,5,6,25,26]$, such recommendations are not reflected in the diets of American youth $[13,16,17]$. The 2005 Dietary Guidelines for Americans [DGA] provide fruit and vegetable recommendations based on caloric requirements [26]. A recent study used participant age, sex, and self-reported physical activity level to estimate caloric requirements and then used dietary recall data from 2003-2004 NHANES to estimate the percent of adolescents meeting current DGA recommendations for fruit and vegetable intake based on caloric requirements [17]. According to the study, $6.2 \%$ of adolescents aged $12-18$ 
Table 1 Current recommendations for dietary factors associated with reduced cancer risk

\begin{tabular}{|c|c|}
\hline Recommendation & Source \\
\hline \multicolumn{2}{|l|}{ Fruit and vegetable consumption } \\
\hline $\begin{array}{l}\text { - Eat five or more servings of a variety of vegetables and } \\
\text { fruits each day. }\end{array}$ & ACS [3] \\
\hline - Eat vegetables and fruits daily; limit juice intake. & $\mathrm{AHA}[25]$ \\
\hline $\begin{array}{l}\text { - Eat at least five servings (at least } 400 \mathrm{~g} \text { or } 14 \mathrm{oz} \text { ) of a } \\
\text { variety of non-starchy vegetables and of fruits every day. }\end{array}$ & AICR [1] \\
\hline $\begin{array}{l}\text { - Consume sufficient amounts of fruits and vegetables while } \\
\text { staying within energy needs; choose a variety of fruits and } \\
\text { vegetables each day. }\end{array}$ & DGA [26] \\
\hline $\begin{array}{l}\text { - Have a diet which includes at least } 400 \mathrm{~g} \text { per day of total } \\
\text { fruits and vegetables. }\end{array}$ & O [6] \\
\hline \multicolumn{2}{|l|}{ Whole grain consumption } \\
\hline $\begin{array}{l}\text { - Chose whole grains in preference } \\
\text { grains and sugars. }\end{array}$ & ACS [3] \\
\hline $\begin{array}{l}\text { - Eat whole grain breads and cereals rather than refined } \\
\text { grain products. }\end{array}$ & AHA [25] \\
\hline $\begin{array}{l}\text { - Eat relatively unprocessed grains and/or legumes with every } \\
\text { meal. }\end{array}$ & AICR [1] \\
\hline $\begin{array}{l}\text { - Consume } 3 \text { or more ounce-equivalents of whole-grain } \\
\text { products per day; At least half of grains consumed should } \\
\text { come from whole grains. }\end{array}$ & DGA [26] \\
\hline \multicolumn{2}{|l|}{ Healthy weight } \\
\hline $\begin{array}{l}\text { - Choose foods and beverages in amounts that help achieve } \\
\text { and maintain a healthy weight through life. }\end{array}$ & ACS [3] \\
\hline $\begin{array}{l}\text { - Balance dietary calories with physical activity to maintain } \\
\text { normal growth. }\end{array}$ & AHA [25] \\
\hline $\begin{array}{l}\text { - Be as lean as possible within the normal range of body } \\
\left.\text { weight (BMI of } 18.5-24.9 \mathrm{~kg} / \mathrm{m}^{2}\right) \text {. }\end{array}$ & AICR [1] \\
\hline $\begin{array}{l}\text { - To maintain body weight in a healthy range, balance } \\
\text { calories from foods and beverages with calories expended. }\end{array}$ & DGA [26] \\
\hline $\begin{array}{l}\text { - Maintain weight such that BMI is in the range of } 18.5-24.9 \\
\mathrm{~kg} / \mathrm{m}^{2} \text {, and avoid weight gain during adult life. }\end{array}$ & WHO [6] \\
\hline
\end{tabular}

years met DGA fruit consumption recommendations, and $2.2 \%$ met vegetable consumption recommendations [17]. Only $0.9 \%$ met the DGA recommendations for both fruit and vegetable intake [17]. Dietary recommendations from other health organizations such as ACS and AICR/WCRF recommend five or more servings of fruits and vegetables daily [1,3]. In 2009, 22.3\% of U.S. high school students nationwide had eaten fruit and vegetables five or more times per day during the seven days before the national YRBS survey [13]. The percentage of students who ate fruits and vegetables five or more times per day decreased significantly during 1999-2005 (23.9\% - 20.1\%; p < .05) and did not change significantly during 2005-2009 (20.1\% - 22.3\%) [13].

\section{Whole grains}

Consumption of unprocessed whole grains is thought to be associated with a decreased cancer risk, and the 2005 DGA recommend consuming 3 or more 1-ounce-equivalent servings of grain daily, of which at least half should be whole grains $[1,3,5,26]$. Major sources of whole grains
Table 2 Current recommendations for dietary factors associated with increased cancer risk

\begin{tabular}{|c|c|c|}
\hline Factor & Recommendation & Source \\
\hline \multicolumn{3}{|c|}{ Red and processed meat } \\
\hline - Limit c & processed and red meats. & ACS [3] \\
\hline $\begin{array}{l}\text { - People } \\
\text { oz) a we }\end{array}$ & $\begin{array}{l}\text { at to consume less than } 500 \mathrm{~g} \mathrm{(} 18 \\
\text { ny to be processed. }\end{array}$ & AlCR [1] \\
\hline $\begin{array}{l}\text { - When } \\
\text { lean, lov }\end{array}$ & paring meat, make choices that are & DGA [26] \\
\hline - Those & etarian are advised to moderate & WHO [6] \\
\hline
\end{tabular}
consumption of preserved meat.

\section{Refined sugars}

- Limit consumption of refined carbohydrates.

- Reduce the intake of sugar-sweetened beverages and AHA [25] foods.

- Avoid sugary drinks. Limit refined, starchy foods.

AICR [1]

- Choose and prepare foods and beverages with little added DGA [26] sugars or caloric sweeteners.

\section{Energy-dense foods}

- Limit consumption of energy-dense foods. Consume 'fast foods' sparingly, if at all.

Salt

- Avoid salt-preserved, salted, or salty foods; preserve foods without using salt. Limit consumption of

processed foods with added salt to ensure an intake of less than $6 \mathrm{~g}$ ( $2.4 \mathrm{~g}$ sodium) a day.

- Reduce salt intake, including salt from processed foods.

- Consume less than 2,300 mg (approximately 1 teaspoon of DGA [26] salt) of sodium per day.

- Overall consumption of salt-preserved foods and salt should WHO [6] be moderate.

\section{Alcohol}

- Drink no more than one drink per day for women or two per day for men.

- Limit alcohol consumption to no more than two drinks for men and one for women a day.

- Alcohol should not be consumed by children and adolescents.

- Consumption of alcoholic beverages is not recommended: if consumed, do not exceed two units ${ }^{9}$ per day.

\section{Mycotoxins}

- Do not eat moldy grains or legumes.

- Minimize exposure to aflatoxin in foods.

Arsenic

- Avoid use of any source of water that may be contaminated with arsenic

consumed among youth include yeast breads, popcorn, and ready-to-eat breakfast cereals [30]. NHANES data from 1999 to 2002 indicated that only 3.4\% of adolescents 12-18 years met the DGA recommendations for whole grain consumption [18]. The national YRBS does not include questions about grain consumption [13].

\section{Healthy weight}

Maintaining a healthy weight is also recommended for overall health and in support of cancer prevention 
[1-3,26-28]. When assessing the weight of U.S. children and adolescents, the 2000 CDC growth charts are often used [31]. The 2000 CDC growth charts are based on data from five cross-sectional, nationally representative health examination studies conducted during 1963-65, 1966-70, 1971-74, 1976-80, and 1988-94 [32]. The 2000 CDC growth charts provide height-for-age, weight-forage, and BMI-for-age percentiles in girls and boys [32]. Although the definitions of childhood overweight and obesity vary somewhat in the current literature, experts recently recommended that children with a BMI greater than or equal to the $85^{\text {th }}$ percentile on the 2000 CDC growth charts of BMI-for-age (based on measured height and weight) be classified as overweight and children with a BMI greater than or equal to the $95^{\text {th }}$ percentile be classified as obese [33]. The prevalence of obesity among U.S. adolescents ages 12-19 was approximately $5.0 \%$ in the early 1970 's, but prevalence rates reached $18.1 \%$ among adolescents during the 2007-2008 NHANES [34]. This increase in obesity over time has been observed across gender, racial, and ethnic groups [34]. Data from the 2009 national YRBS indicated that $12.0 \%$ of high school students nationwide were obese and $15.8 \%$ of students were overweight based on selfreported height and weight [13]. Significant linear increases occurred in the percentage of students who were obese $(10.7 \%-12.0 \%)$ and who were overweight (14.4\% - 15.8\%) during 1999 - 2009 [13].

\section{Energy-dense foods}

Current AICR dietary guidelines for cancer prevention specifically recommend limiting energy-dense foods [1]. A diet rich in fruits, vegetables and whole grains, with limited amounts of refined sugars is likely to be low in energy-dense foods and conducive to maintaining a healthy weight. However, as can be seen from the statistics above, American youth are not consuming the recommended amounts of fruits, vegetables and whole grains, suggesting that they may be over-consuming more energy-dense foods $[16,18,19]$.

\section{Refined sugars}

Desserts, dairy desserts, and candy are substantial contributors of refined sugar to the diets of Americans $[16,18,35]$. Sugar-sweetened beverages (SSBs), including soda, sports drinks, fruit drinks and punches, low calorie drinks, sweetened tea, and other sweetened beverages, are another notable source of refined sugars in the diet. According to NHANES data from 1988 through 2004, approximately $80 \%$ of adolescents aged $12-19$ years had consumed SSBs on the survey day [19]. Among those who consumed SSBs on the survey day, the mean amount consumed on the day of the survey increased from 30.3 ounces in 1988-1994 to 32.7 ounces in 1999-
2004 [19]. The increase in SSB consumption appears primarily to have occurred among young males $[19,36,37]$. The national YRBS asks specifically about soda or pop consumption rather than all SSBs [13]. In the 2009 national YRBS, $29.2 \%$ of high school students nationwide had drunk a can, bottle, or glass of soda or pop [not including diet soda or diet pop] at least one time per day during the seven days before the survey [13]. Data from national YRBS indicates that this percentage has decreased in recent years, from $33.8 \%$ in 2007 to $29.2 \%$ in 2009 [13].

\section{Red and processed meat}

Several recommendations encourage limiting consumption of red and processed meats [1-3,6]. The USDA estimates that, in general, Americans consume about 110 pounds (49.9 kilograms) of red meat per year, which equals to approximately 3 ounces per day $[38,39]$. Furthermore, data from both NHANES III (1988-1994) and NHANES 1999-2002 indicate that adolescents ages 12-16 consumed an average of 1-2 servings of red meat per day and just under one serving of processed meat per day [16]. The national YRBS does not include questions about meat consumption [13].

\section{Salt}

Although dietary guidelines recommend limiting salt consumption, sodium intake among youth has increased over the past decade based on NHANES data $[1,2,5,6,20-22,40]$. This increase is likely due, in part, to the rise in the consumption of heavily processed foods, which tend to have high sodium contents [40]. The 2005 DGA recommend limiting sodium consumption to less than $2300 \mathrm{mg} /$ day [18]. However, 2005-2006 NHANES data indicate males and females ages $12-19$ years consumed approximately $4266 \mathrm{mg} /$ day and 2950 $\mathrm{mg} /$ day respectively $[20,25]$. Youth were consuming slightly less sodium in 2001-2002 according to NHANES data $(3990 \mathrm{mg} /$ day among males and $2831 \mathrm{mg} /$ day among females) but were still above the DGA recommendation [22]. Salt consumption is not assessed on the national YRBS [13].

\section{Alcohol}

Dietary recommendations also address alcohol consumption and generally state that if alcoholic beverages are consumed, it should be done in moderation [1-3,5]. However, the 2005 DGA state alcohol should not be consumed by children and adolescents [26]. Furthermore, an early age at first drink (specifically under the age of 18) may be associated with an increased risk of alcohol dependence and other alcohol use disorders in adulthood [41]. In 1984, the Federal Uniform Drinking Age Act (Public Law 98-363) required states to enforce 
an age minimum of 21 years for purchasing and/or publically possessing alcoholic beverages. Although some literature suggests that this law was associated with a decrease in alcohol consumption among minors [42], youth in the U.S. continue to have access to alcohol $[13,43]$. NHANES data from 1999-2004 showed 39\% of adolescents aged 12-17 years had at least one drink of alcohol in their lifetime, and $21 \%$ had at least one drink of alcohol during the 30 days before the survey [43]. According to data from the 2009 national YRBS, $72.5 \%$ of high school students nationwide had had at least one drink of alcohol on at least one day during their life, and $41.8 \%$ of students had at least one drink of alcohol on at least one day during the thirty days before the survey (i.e., current alcohol use) [13]. During 1999 - 2009, the percentage of students who reported current alcohol use decreased (50.0\%-41.8\%) [13].

\section{Mycotoxins}

Cancer prevention guidelines also recommend avoiding consumption of moldy grains and legumes which may be contaminated with mycotoxins, particularly aflatoxin $[1,2,6]$. Aflatoxin is one of many naturally occurring mycotoxins which can grow on agricultural commodities such as grains and nuts in the field and in storage and is considered to be a known carcinogen $[1,2,6,43]$. Ochratoxin and fumonisin are other mycotoxins classified by IARC as "possibly carcinogenic" to humans [44]. The FDA has established action levels to control the levels of mycotoxins in food and animal feed, but there is no system in place to monitor exposure among adolescents in the United States [45].

\section{Arsenic}

AICR recommends avoiding the use of any source of water that may be contaminated with arsenic (Table 2). Arsenic is classified by IARC as "carcinogenic to humans," and exposure to arsenic within the general U. S. population can occur not only through water consumption but also through consumption of contaminated meats, grains, produce and seafood [24,44]. According to the Fourth National Report on Human Exposure to Environmental Chemicals, the mean urinary arsenic levels [in $\mu \mathrm{g} / \mathrm{L}$ ] among children ages 6-11 years and 12 - 19 years were 7.08 (5.66-8.84) and 8.55 (7.349.97) respectively [24].

\section{Conclusion}

Dietary guidelines for cancer prevention are similar across prominent public health organizations. In spite of a general scientific consensus on the importance of a healthy diet for cancer prevention, the actual diets of a large proportion of America's youth are not aligned with these dietary recommendations. Pre-adolescents and adolescents tend to fall short of recommendations for fruit, vegetable, and whole grain consumption. Furthermore, an unhealthy proportion of their diet is composed of energy-dense foods that are high in fat (such as red and processed meats), refined sugar (such as refined grains and SSBs), and/or salt.

Improving dietary behaviors poses many challenges. Among youth, dietary behaviors are influenced by numerous factors at multiple levels: individual, interpersonal, community, and society levels [11]. Identifying key influential factors may inform future public health policies and practices. For example, adolescents generally do not have the same level of control over their food intake that adults do, and much of the responsibility to support healthy eating habits falls on parents [46]. Parents tend to be influenced by socioeconomic factors, and changes to food pricing offer a potential strategy for dietary improvements [11]. Another example is the school food environment which plays a key role in proper nutrition. Millions of children and adolescents rely on federally-supported school breakfast and lunch programs $[47,48]$. Yet participation in the school meal program has been shown to be associated with an increased prevalence of excessive sodium intake [49]. Such findings suggest that improvements to the school meal program alone could have a positive impact on the quality of youth's diets.

When assessing the dietary behaviors among youth related to cancer prevention, we face several limitations. First, dietary intake data from both NHANES and YRBS rely heavily on self-reported information, which can be subject to bias and error. NHANES dietary intake data are collected via multiple 24-hour dietary recalls which may be less prone to error than other dietary recall methods [50]. NHANES data for BMI is based on height and weight measurements which are considered more accurate than self-reported height and weight, as are used in the national YRBS [51]. Second, dietary recommendations for cancer prevention tend to be based on knowledge related to adults' dietary behaviors, and there is insufficient evidence to know how strongly dietary habits during childhood predict lifetime dietary patterns [52-55]. Epidemiological studies suggest that unhealthy dietary habits that develop early in life and persist into adulthood may increase the risk of some cancer types, but additional research is needed to better understand the degree to which childhood dietary patterns relate to subsequent cancer risk later in life [56]. Additionally, the relationship between cancer and certain diet-related factors may not necessarily be the same throughout the lifespan, as has been observed for obesity and breast cancer $[57,58]$. Third, our understanding of the risks associated with potential carcinogens in the diet are often based on the effects of such contaminants in 
adults. These contaminants may be metabolized differently in a child's or adolescent's body due to differences in body size and composition, and youth have a "unique vulnerability" to the effects of chemical, physical, and biological agents [59-61]. This difference may have implications for age-specific recommendations regarding potential carcinogens in youth diets.

Cancer etiology and cancer risk assessment are dynamic fields of scientific investigation, and our understanding about the role of diet in cancer occurrence is continually evolving. As a result, the dietary recommendations for cancer prevention examined in this review may change over time. For example, although the consumption of fruits and vegetables has long been associated with lower risks for certain types of cancers, recent research suggests that the consumption of fruits and vegetables may not be as protective against cancer as had been previously assumed $[62,63]$. The potential cancer risks associated with low levels of exposure to certain chemicals are being reassessed in the face of evidence of upstream effects such as changes in hormone levels and immune function [64]. Such chemicals are not addressed in the major dietary guidelines for cancer prevention, and more research is needed to determine if the levels of exposure to these contaminants in the United States is cause for a health concern [24]. Research evaluating the health effects of these chemicals is particularly important to protect the health of children, who are generally thought to be more susceptible to carcinogens than adults [65]. In the future, further advances in our scientific knowledge may reduce current uncertainties about diet and cancer and present new opportunities to reduce cancer risk.

This review illustrates discrepancies between expert recommendations about diet and cancer and actual dietary practices among youth and points to the need for more research to better promote the translation of science into practice. Data from the 2003 Health Information National Trends Survey (HINTS) suggests that at least half of the general population in the U.S. is aware that a healthy diet may reduce one's cancer risk [66]. Although education and awareness about healthy eating for cancer prevention are important, interventions that make healthy options the default choice regardless of education, income, or other societal factors, change the environmental context in which dietary choices are made and may have a greater impact on the eating behaviors of America's youth [67]. Future research should focus on developing and evaluating policies and interventions at the community, state and national levels for aligning the diets of American youth with the evolving scientific evidence regarding the role of diet in cancer incidence, as well as monitoring the long-term impact of different dietary patterns in childhood on cancer incidence later in life. If such public health efforts were successful, it could potentially reduce future cancer rates and improve the overall health of America's youth $[4,11]$.

\section{Acknowledgements and Funding}

This research was supported in part by an appointment $(\mathrm{DMH})$ to the Research Participation Program at the Centers for Disease Control and Prevention administered by the Oak Ridge Institute for Science and Education through an interagency agreement between the U.S. Department of Energy and CDC. We would like to thank Lori A. (Loria) Pollack, MD, MPH in the Division of Cancer Prevention and Control, CDC, for her helpful comments and contributions to earlier drafts of this manuscript. The findings and conclusions in this report are those of the authors and do not necessarily represent the official position of the Centers for Disease Control and Prevention.

\section{Authors' contributions}

DH participated in the conception and design of the paper, carried out the initial literature review, and contributed to drafting and critically revising the manuscript. MW participated in the conception and design of the paper and contributed to drafting and critically revising the manuscript. Both authors have read and approved the final manuscript.

\section{Competing interests}

The authors declare that they have no competing interests.

Received: 22 November 2010 Accepted: 1 June 2011

Published: 1 June 2011

\section{References}

1. American Institute for Cancer Research: Food, nutrition, physical activity, and the prevention of cancer: a global perspective. World Cancer Research Fund Washington, DC 2007.

2. Key TJ, Schatzkin A, Willet WC, Allen NE, Spencer EA, Travis RC: Diet, nutrition and the prevention of cancer. Public Health Nutr 2004, 7(1A):187-200

3. Kushi LH, Byers T, Doyle C, Bandera EV, McCollough M, Gansler T, Andrews KS, Thun MJ: American Cancer Society Guidelines on Nutrition and Physical Activity for cancer prevention: reducing the risk of cancer with healthy food choices and physical activity. CA Cancer J Clin 2006, 56(5):254-281.

4. Uauy R, Solomons N: Diet, nutrition, and the life-course approach to cancer prevention. J Nutr 2005, 135(Suppl 12):2934S-2945S.

5. Willett WC: Diet and nutrition. In Cancer Epidemiology and Prevention.. edition. Edited by: Schottenfeld D, Fraumeni JF. New York, NY: Oxford University Press; 2006:405-421.

6. World Health Organization: Diet, nutrition, and the prevention of chronic diseases. Report of the Joint World Health Organization/Food and Agriculture Organization Expert Consultation. WHO Technical Report Series 2003, 916.

7. Neuhouser ML: Dietary Assessment in Behavioral Medicine. In Handbook of Behavioral Medicine: Methods and Application. Edited by: Andrew Steptoe. New York: Springer; 2010:49-58.

8. Meyskens FL, Szabo E: Diet and cancer: the disconnect between epidemiology and randomized clinical trials. Cancer Epidemiol Biomarkers Prev 2005, 14(6):1366-9.

9. Gibson TM, Ferrucci LM, Tangrea JA, Schatzkin A: Epidemiological and Clinical Studies of Nutrition. Seminars in Oncology 2010, 37:282-296.

10. Prentice RL: Dietary assessment and the reliability of nutritional epidemiology research reports. JNC 2010, 9:583-585.

11. Story MD, Neumark-Sztainer D, French S: Individual and environmental influences on adolescent eating behaviors. J Am Diet Assoc 2002, 102(Suppl 3):S40-51.

12. Centers for Disease Control and Prevention National Center for Health Statistics: National health and nutrition examination survey [http://www.cdc gov/nchs/nhanes.htm], Accessed June 29, 2010.

13. Centers for Disease Control and Prevention: Youth Risk Behavior Surveillance - United States, 2009. MMWR Surveill Summ 2010, 59(SS-5) 
14. United States Department of Agriculture website. [http://www.usda.gov/ wps/portal/usda/usdahome].

15. Dwyer J, Picciano MF, Raiten DJ: Collection of food and dietary supplement intake data: what we eat in America - NHANES. J Nutr 2003, 133:590-600.

16. Bradlee ML, Singer MR, Qureshi MM, Moore LL: Food group intake and central obesity among children and adolescents in the Third National Health and Nutrition Examination. Public Health Nutr 2010, 13(6):797.

17. Kimmons J, Gillespie C, Seymour J, Serdula M, Blanck HM: Fruit and vegetable intake among adolescents and adults in the United States: percentage meeting individualized recommendations. Medscape J Med 2009, 11(1):26

18. Carlson A, Mancino L, Lino M, United States Department of Agriculture: Grain Consumption by Americans. Nutrition Insight 2005, 32: [http://www. wheatfoods.org/_FileLibrary/Product/73/USDA\%20Grain\%20Consumption\% 20By\%20Americans\%202005.pdf], Accessed January 29, 2010.

19. Wang YC, Bleich SN, Gortmaker SL: Increasing caloric contribution from sugar-sweetened beverages and $100 \%$ fruit juices among US children and adolescents, 1988-2004. Pediatrics 2008, 121(6):e1604-14.

20. U.S. Department of Agriculture, Agricultural Research Service: Nutrient Intakes from Food: Mean Amounts Consumed per Individual, One Day, 200520062008 [http://www.ars.usda.gov/ba/bhnrc/fsrg].

21. U.S. Department of Agriculture, Agricultural Research Service: Nutrient Intakes from Food: Mean Amounts Consumed per Individual, One Day, 200320042007 [http://www.ars.usda.gov/ba/bhnrc/fsrg].

22. U.S. Department of Agriculture, Agricultural Research Service: Nutrient Intakes from Food: Mean Amounts Consumed per Individual, One Day, 200120022006 [http://www.ars.usda.gov/ba/bhnrc/fsrg].

23. Fryar CD, Merino MC, Hirsch R, Porter KS: Smoking, alcohol use, and illicit drug use reported by adolescents aged 12-17 years: United States, 1999-2004. Natl Health Stat Report 2009, 15:1-23.

24. Centers for Disease Control and Prevention: Fourth national report on human exposure to environmental chemicals National Center for Environmental Health, Division of Laboratory Sciences; 2009 [http://www. cdc.gov/exposurereport/], Accessed January 9, 2009.

25. Gidding SS, Dennison BA, Birch LL, Daniels SR, Gilman MW, Lichtenstein AH, Rattay KT, Steinberger J, Stettler N, Van Horn L: Dietary recommendations for children and adolescents: A guide for practitioners. Consensus statement from the American Heart Association. Circulation 2005, 112:2061-2075.

26. U.S. Department of Health and Human Services and U.S. Department of Agriculture: Dietary Guidelines for Americans, 2005. 6 edition. Washington DC: U.S. Government Printing Office; 2005

27. Reeves GK, Pirie K, Beral V, Green J, Spencer E, Bull D: Cancer incidence and mortality in relation to body mass index in the Million Women Study: cohort study. Br Med J 2007, 335(7630):1134.

28. Renehan AG, Roberts DL, Dive C: Obesity and cancer: Pathophysiological and biological mechanisms. Arch Physiol Biochem 2008, 114(1):71-83.

29. International Agency for Research on Cancer: In Weight control and physical activity. Edited by: Vanio H, Bianchini F. Lyon, France: IARC Press; 2002:

30. Burgess-Champoux TL, Larson NI, Neumark-Sztainer DR, Hannan PJ, Story MT: Longitudinal and secular trends in adolescent whole-grain consumption, 1999-2004. Am J Clin Nutr 2010, 91(1):154-159.

31. Centers for Disease Control and Prevention: CDC Clinical Growth Charts [http://www.cdc.gov/growthcharts/clinical_charts.htm], Accessed December 9, 2009.

32. Kuczmarsk RJ, Ogden CL, Guo SS, Grummer-Strawn LM, Flegal KM, Mei Z: 2000 CDC Growth Charts for the United States: methods and development. Vital Health Stat 2002, 11(246):1-190.

33. Barlow SE: Expert committee recommendations regarding the prevention, assessment, and treatment of child and adolescent overweight and obesity: summary report. Pediatrics 2007, 120(Suppl 4): S164-92.

34. Ogden C, Carroll M: Prevalence of obesity among children and adolescents: United States, trends 1963 - 1965 through 2007 - 2008. NCHS Health E-Stats 2010 [http://www.cdc.gov/nchs/data/hestat/ obesity_child_07_08/obesity_child_07_08.htm], Accessed June 29, 2010.

35. Bachman JL, Reedy J, Subar AF, Krebs-Smith SM: Sources of food group intakes among the US population, 2001-2002. J Am Diet Assoc 2008, 108(5):804-14.
36. Bremer AA, Auinger $P$, Byrd RS: Sugar-sweetened beverage intake trends in US adolescents and their association with insulin resistance-related parameters. J Nutr Metab 2010.

37. Nelson MC, Neumark-Sztainer D, Hannan PJ: Five-year longitudinal and secular shifts in adolescent beverage intake: findings from project EAT (Eating Among Teens)-II. J Am Diet Assoc 2009, 109(2):308-12.

38. Wells HF, Buzby JC: Dietary assessement of major trends in U.S. food consumption, 1970-2005. Economic Information Bulletin 2008, 3.

39. U.S. Department of Agriculture: Loss-adjusted food availability 2009 [http:// www.ers.usda.gov/Data/FoodConsumption/FoodGuidelndex.htm\#meat], Accessed December 9, 2009.

40. Schreuder MF, Bokenkamp A, van Wijk JA: Salt intake in children: increasing concerns? Hypertension 2007, 49(2):e10, author reply: e11.

41. Dawson DA, Goldstein RB, Chou SP, Ruan WJ, Grant BF: Age at first drink and the first incidence of adult-onset DSM-IV alcohol use disorders. Alcohol Clin Exp Res 2008, 32(12):2149-2160.

42. Wagenaar AC, Toomey TL: Effects of minimum drinking age laws: review and analyses of the literature from 1960 to 2000. I Stud Alcohol Suppl 2002, 14:206-225.

43. Food and Drug Administration: Mycotoxins in domestic and imported foods. Compliance Program Guidance Manual. Molecular Biology and Natural Toxins 2006, Chapter 7.

44. International Agency for Research on Cancer: IARC monographs on the evaluation of carcinogenic risk to humans. Complete list of agents evaluated and their classifications 2009 [http://monographs.iarc.fr/ENG/Classification/ index.php], Accessed January 27, 2010.

45. Food and Drug Administration: Guidance for industry: Action levels for poisonous or deleterious substances in human food and animal feed 2000 [http://www.fda.gov/Food/GuidanceComplianceRegulatorylnformation/ GuidanceDocuments/ChemicalContaminantsandPesticides/ucm077969. htm\#afla], Accessed April 21, 2010.

46. Savage JS, Fisher JO, Birch LL: Parental influence on eating behavior: conception to adolescence. J Law Me Ethics 2007, 35(1):22-34.

47. United States Department of Agriculture: The school breakfast program [http://www.fns.usda.gov/cnd/Breakfast/AboutBFast/SBPFactSheet.pdf], Accessed May 19, 2010.

48. United States Department of Agriculture: National school lunch program [http://www.fns.usda.gov/cnd/Lunch/AboutLunch/NSLPFactSheet.pdf], Accessed May 19, 2010.

49. Clark MA, Fox MK: Nutritional quality of the diets of US public school children and the role of the school meal programs. J Am Diet Assoc 2009, 109(2 Suppl):S44-56.

50. Burrows TL, Martin RJ, Collins CE: A systematic review of the validity of dietary assessment methods in children when compared with the method of doubly labeled water. J Am Diet Assoc 2010, 110(10):1501-1510.

51. Brener ND, McManus T, Galuska DA, Lowry R, Wechsler H: Reliability and validity of self-reported height and weight among high school students. J Adolesc Health 2003, 32:281-287.

52. Cutler GJ, Flood A, Hannan P, Neumark-Sztainer D: Major patterns of dietary intake in adolescents and their stability over time. Journal of Nutrition 2008, 139(2):323-8.

53. Mikkila V, Rasanen L, Raitakari OT, Pietinen P, Viikari J: Consistent dietary patterns identified from childhood to adulthood: The Cardiovascular Risk in Young Finns Study. Br J Nutr 2005, 93:923-31.

54. Lake A, Mathers JC, Rugg-Gunn AJ, Adamson AJ: Longitudinal change in food habits between adolescence (11-12 years) and adulthood (32-33 years): the ASH30 Study. J Public Health 2006, 28(1):10-16.

55. Te Velde SJ, Twisk JWR, Brug J: Tracking of fruit and vegetable consumption from adolescence into adulthood and its longitudinal association with overweight. Br J Nutr 2007, 98:431-8.

56. Fuemmeler BF, Pendzich MK, Tercyak KP: Weight, dietary behavior, and physical activity in childhood and adolescence: implications for adult cancer risk. Obes Facts 2009, 3:179-186.

57. Baer HJ, Tworoger SS, Hankinson SE, Willett WC: Body Fatness at Young Ages and Risk of Breast Cancer Throughout Life. Am J Epidemiol 2010, 171:1183-1194

58. Berstad P, Coates RJ, Bernstein L, Folger SG, Malone KE, Marchbanks PA, Weiss LK, Liff JM, McDonald JA, Strom BL, Simon MS, Deapen D, Press MF, Burkman RT, Spirtas R, Ursin G: A case-control study of body mass index 
and breast cancer risk in white and African-American women. Cancer Epidemiol Biomarkers Prev 2010, 19(6):1532-44.

59. Anderson LM, Diwan BA, Fear NT, Roman E: Critical windows of exposure for children's health: cancer in human epidemiological studies and neoplasms in experimental animal models. Environ Health Perspect 2001, 109:573-94.

60. World Health Organization: Healthy environments for children: WHO backgrounder No3 2003 [http://www.who.int/world-health-day/previous/ 2003/backgrounder/en/], Accessed May 19, 2010.

61. Wild CP, Kleinjans J: Children and increased susceptibility to environmental carcinogenesis: evidence or empathy? Cancer Epidemiol Biomarkers Prev 2003, 12:1384-9

62. Boffetta $P$, Couto E, Wichmann J, Ferrari P, Trichopoulos D, et al: Fruit and vegetable intake and overall cancer risk in the European Prospective Investigation into Cancer and Nutrition (EPIC). J Natl Cancer Inst 2010, 102(8):529-37.

63. Willett WC: Fruits, vegetables, and cancer prevention: Turmoil in the produce section. J Natl Cancer Inst 2010, 102(8).

64. Woodruff TJ, Zeise L, Axelrad DA, Guyton KZ, Janssen S, Miller M: Meeting report: moving upstream-evaluating adverse upstream end points for improved risk assessment and decision-making. Environ Health Perspect 2008, 116(11):1568-75.

65. Firestone M: Protecting children from environmental risks throughout each stage of their childhood. J Expo Sci Environ Epidemiol 2010, 20(3):227-8.

66. Hawkins NA, Berkowitz Z, Peipins LA: What Does the Public Know About Preventing Cancer? Results From the Health Information National Trends Survey (HINTS). Health Educ Behav 2010, 37(4):490-503.

67. Frieden TR: A framework for public health action: The health impact pyramid. Am J Public Health 2010, 100(4):590-595.

doi:10.1186/1475-2891-10-60

Cite this article as: Holman and White: Dietary behaviors related to cancer prevention among pre-adolescents and adolescents: the gap between recommendations and reality. Nutrition Journal 2011 10:60.

\section{Submit your next manuscript to BioMed Central and take full advantage of:}

- Convenient online submission

- Thorough peer review

- No space constraints or color figure charges

- Immediate publication on acceptance

- Inclusion in PubMed, CAS, Scopus and Google Scholar

- Research which is freely available for redistribution

Submit your manuscript at www.biomedcentral.com/submit
Biomed Central 